\title{
Prevalence and Clinical Profile of Patients with Polycystic Ovary Syndrome- A Hospital Based Study
}

\author{
H. K. Cheema ${ }^{1}$, Rajiv Arora ${ }^{2}$ \\ ${ }^{1}$ Associate Professor, Department of Gynaecology, PIMS, Jalandhar, Punjab, India. \\ ${ }^{2}$ Professor and HOD, Department of Physiology, PIMS, Jalandhar, Punjab, India.
}

\section{ABSTRACT}

\section{BACKGROUND}

Polycystic ovary syndrome (PCOS) is said to be the commonest endocrine disorder of women of reproductive age with a heterogeneous presentation, which includes elevated androgen levels, menstrual irregularities, and/or small cysts on one or both ovaries. (1) On an average, it is affecting 4-8\% of women of reproductive age.(2) Despite being an endocrine disease, it is also influenced by obesity and sedentary lifestyle. It is greatly affecting an-ovulatory infertility status of women affected by PCOS. We wanted to study prevalence of polycystic ovarian syndrome in patients coming to OPD \& to study the clinical profile of PCOS among women of reproductive age group along with the incidence of obesity \& influence of sedentary lifestyle.

\section{METHODS}

This was a hospital based cross-sectional study conducted among women of reproductive age group (15-45 years) attending Gynae. OPD at PIMS, Jalandhar. Women of reproductive age group (15-45 years) attending Gynae. OPD at PIMS, Jalandhar were enrolled in the study.

\section{RESULTS}

Out of the total 1140 cases examined during the study period, PCOS was diagnosed in 107 cases, giving prevalence of PCOS as $9.38 \%$ in the present study. Most of the cases (39.25\%) were in the age group of 13-20 years Prevalence of PCOS, in the age group of $21-30$ years was $27.10 \%$ and in age group of $41-50$ years, it was only $11.21 \%$. Prevalence of overweight/obesity was $45.79 \%$ in cases of PCOS. Patter of education distribution showed highest prevalence in less educated (primary education) in $36.44 \%$ with less prevalence in higher education group as $13.08 \%$ (Table 4). Most common menstrual abnormality seen among cases of PCOS was delayed menses with (34.57\%) or without (27.10\%) hypo-menorrhoea. Isolated hypo-menorrhoea was seen in $20.56 \%$ cases (Table 5). Out of total 107 cases, 48 (44.85\%) were married (Table 6). Out of 48 married females, prevalence of infertility was $66.66 \%$ with $58.33 \%$ cases of primary infertility while $8.33 \%$ cases of secondary infertility (Table 7). History of regular intake of junk foods was given by $57.94 \%$ cases (Table 8). Sedentary lifestyle was observed in $49.53 \%$ cases (Table 9 ).

\section{CONCLUSIONS}

Though PCOS is a heterogeneous endocrine disease having genetic factors, environmental and nutritional factors affect its incidence a lot. Eating high calorie food with sedentary lifestyle and obesity affect the incidence and severity of PCOS. We have found in the present study that incidence of an-ovulatory infertility is also high. Since PCOS is a lifestyle disease adversely affecting fertility and physical appearance of the person, it can be prevented by modification of lifestyle, enabling girls to live a healthy life.

\section{KEY WORDS}

Polycystic Ovaries, Endocrine, Obesity, Infertility
Corresponding Author:

Dr. Rajiv Arora,

Professor and HOD,

Department of Physiology,

PIMS, Jalandhar, Punjab, India.

E-mail: drrajivarora@yahoo.co.in

DOI: $10.14260 /$ jemds $/ 2019 / 560$

Financial or Other Competing Interests: None.

How to Cite This Article:

Cheema HK, Arora R. Prevalence and clinical profile of patients with polycystic ovary syndrome- a hospital based study. J. Evolution Med. Dent. Sci. 2019;8(32):25732576, DOI: 10.14260/jemds/2019/560

Submission 24-06-2019,

Peer Review 24-07-2019,

Acceptance 01-08-2019,

Published 12-08-2019. 


\section{BACKGROUND}

Polycystic ovary syndrome (PCOS) is said to be the commonest endocrine disorder of women of reproductive age with a heterogeneous presentation, which includes elevated androgen levels, menstrual irregularities, and/or small cysts on one or both ovaries.(1) On an average, it is affecting $4-8 \%$ of women of reproductive age.(2) It is the commonest cause of anovulatory infertility, and around $90-95 \%$ of women with anovulatory infertility presenting to infertility clinics are affected by the syndrome ${ }^{(3)}$ Main characteristic features include menstrual disturbances, hyperandrogenism \& polycystic ovaries. Up to $70 \%$ of women with hyperandrogenism present with hirsutism, or excess body hair. Acne, though considered less specific, is also a marker of hyperandrogenism.(4),(5) Environmental factors implicated in PCOS (e.g., obesity) can be exacerbated by poor dietary choices and physical inactivity; play a role.(6) The principal concern that has been expressed is the inclusion of genetically determined ovarian disorder characterized by excessive androgen production and that the heterogeneity of PCOS can be explained by the interaction of this disorder with environmental factors, notably dietary. $(7,8)$

The reproductive and metabolic features of PCOS are sometimes reversible with lifestyle modifications such as weight loss and exercise ${ }^{(9)}$ PCOS is furthermore associated with insulin resistance, accumulation of abdominal fat and obesity (BMI $>30 \mathrm{Kg} / \mathrm{m}^{2}$ ), which is present in approximately $50 \%$ of women with PCOS(10,11) The Rotterdam criteria does not require hyperandrogenism or hyperandrogenaemia alone for diagnosis, but can confirm diagnosis when these are present alongside polycystic ovaries, even in the absence of ovulatory or menstrual dysfunction.(12)

This study has attempted to determine the prevalence and clinical features including epidemiological and lifestyle factors associated with PCOS among women of reproductive age group (15-45 years), coming to Gynae OPD, in Punjab Institute of Medical Sciences, Jalandhar.

We wanted to study prevalence of polycystic ovarian syndrome in patients coming to OPD \& to study the clinical profile of PCOS among women of reproductive age group along incidence of obesity \& influence of sedentary lifestyle.

\section{METHODS}

\section{Study Design}

This was a hospital based cross- sectional study conducted among women of reproductive age group (15-45 years) attending Gynae OPD at PIMS, Jalandhar

\section{Study Population}

Women of reproductive age group (15-45 years) attending Gynae. OPD at PIMS, Jalandhar were enrolled in the study.

\section{Inclusion Criteria}

All patients of reproductive age group attending Gynae. OPD

\section{Exclusion Criteria}

Patients suffering from chronic diseases or already diagnosed diabetes, hypertension were excluded from the study Systematic sampling technique was employed for the study.
Since there are 1200 patients attending Gynae OPD, every six months, sampling fraction obtained was 2 . List of all patients was secured, and every second participant was included in the study. 1140 patients attending Gynae. OPD in PIMS were studied.

\section{Study Period}

December 2017- November 2018

\section{Study Strategy}

The study was done by administering Pre-designed Prestructured questionnaire. Prior to the study, informed written consent of the participant was obtained.

\section{Study Tools}

Predesigned Pre-structured questionnaire comprising variables like age, education, occupation, marital history and type of family. History of dietary pattern was recorded using pre-structured questionnaire based on consumption pattern, frequency of meals, type of meal, vegetables and fruits consumption, daily water intake, consumption of fast food, etc. Physical activity considered in present study was intense physical activity of more than 30 minutes a day for 4- 5 days in week.

\section{Clinical Examination and Diagnostic Criteria}

History of Irregular menstrual cycles, weight gain and hirsutism were recorded. Height and weight was recorded for computing BMI $\left(\mathrm{Kg} / \mathrm{m}^{2}\right)$. Diagnosis was made in accordance to Rotterdam criteria, ${ }^{(9,12)}$ which includes history of oligomenorrhea or amenorrhea, Hyperandrogenism or Clinical hirsutism was observed. Probable cases of PCOS were subjected to Ultrasonography. Free serum Testosterone was done. PCOS on USG were noted. 2 out of these criteria was taken.

\section{Data Analysis}

The data collected during the survey was entered in MS Excel and was analyzed via SPSS (Statistical Package for the Social Sciences) version 21.

\section{Ethics Consideration}

Ethics clearance was taken for the study from Institutional Ethics committee. Informed written consent from the informant was taken before conducting the study. Strict confidentiality was maintained.

\section{RESULTS}

\begin{tabular}{|c|c|c|}
\hline Total Examined Patients & PCOS Diagnosed & Percentage of PCOS \\
\hline 1140 & 107 & $9.38 \%$ \\
\hline \multicolumn{3}{|c|}{ Table 1. Prevalence of PCOS } \\
\hline
\end{tabular}

\begin{tabular}{|c|c|c|}
\hline Years & No. of Cases & Percentage \\
\hline $13-20$ yrs. & 42 & $39.25 \%$ \\
\hline $21-30$ & 29 & $27.10 \%$ \\
\hline $31-40$ & 24 & $22.42 \%$ \\
\hline $41-50$ & 12 & $11.21 \%$ \\
\hline \multicolumn{2}{|c|}{ Table 2. Age Wise Distribution (Out of 107) } \\
\hline
\end{tabular}




\begin{tabular}{|c|c|c|}
\hline Weight & No. of Cases & Percentage \\
\hline Over-weight & 49 & $45.79 \%$ \\
\hline Normal & 32 & $29.90 \%$ \\
\hline Under-weight & 26 & $24.29 \%$ \\
\hline \multicolumn{2}{|c|}{ Table 3. Weight Wise Distribution } \\
\hline
\end{tabular}

\begin{tabular}{|c|c|c|}
\hline Education & No. of Cases & Percentage \\
\hline Illiterate & 30 & $28.03 \%$ \\
\hline Primary & 39 & $36.44 \%$ \\
\hline secondary & 24 & $22.42 \%$ \\
\hline Higher education & 14 & $13.08 \%$ \\
\hline \multicolumn{2}{|c|}{ Table 4. Pattern of Education Distribution } \\
\hline
\end{tabular}

\begin{tabular}{|c|c|c|}
\hline Menstrual Abnormality & No. of Cases & Percentage \\
\hline Delayed menses & 29 & $27.10 \%$ \\
\hline Hypomenorrhea & 22 & $20.56 \%$ \\
\hline D.M.+ Hypomenorrhea & 37 & $34.57 \%$ \\
\hline Amenorrhoea & 06 & $05.60 \%$ \\
\hline Meno-metrorrhagia & 13 & $12.14 \%$ \\
\hline \multicolumn{2}{|c|}{ Table 5. Pattern of Menstrual Abnormalities } \\
\hline
\end{tabular}

\begin{tabular}{|c|c|c|}
\hline Marital Status & No. of Cases & Percentage \\
\hline unmarried & 59 & $55.14 \%$ \\
\hline Married & 48 & $44.85 \%$ \\
\hline \multicolumn{3}{|c|}{ Table 6. Marital Status } \\
\hline
\end{tabular}

\begin{tabular}{|c|c|c|}
\hline Status-Total infertile women out of 48 married women & 32 & $66.66 \%$ \\
\hline Primary infertility & 28 & $58.33 \%$ \\
\hline Secondary infertility (one child) & 04 & $08.33 \%$ \\
\hline Table 7. Infertility Status \\
\hline
\end{tabular}

\begin{tabular}{|c|c|c|}
\hline Habits & No. of Cases & Percentage \\
\hline Normal home cooked food & 45 & $42.05 \%$ \\
\hline Outside junk food with high calories & 62 & $57.94 \%$ \\
\hline \multicolumn{2}{|c|}{ Table 8. Eating Habits } \\
\hline
\end{tabular}

\begin{tabular}{|c|c|c|}
\hline Lifestyle & No. of Cases & Percentage \\
\hline Normal & 33 & $30.84 \%$ \\
\hline Athlete & 21 & $19.62 \%$ \\
\hline Sedentary & 53 & $49.53 \%$ \\
\hline \multicolumn{3}{|c|}{ Table 9. Lifestyle Pattern } \\
\hline
\end{tabular}

Out of the total 1140 cases examined during the study period, PCOS was diagnosed in 107 cases, giving prevalence of PCOS as $9.38 \%$ in the present study. Most of the cases $(39.25 \%)$ were in the age group of 13-20 years Prevalence of PCOS, in age group of 21-30 years was $27.10 \%$ and in age group of 41 50 years, it was only $11.21 \%$. Prevalence of overweight/ obesity was $45.79 \%$ in cases of PCOS. Patter of education distribution showed highest prevalence in less educated (Primary education) in 36.44\% with less prevalence in higher education group as $13.08 \%$ (Table 4) Most common menstrual abnormality seen among cases of PCOS was delayed menses with $(34.57 \%)$ or without $(27.10 \%)$ hypo-menorrhoea. Isolated hypo-menorrhoea was seen in $20.56 \%$ cases (Table 5). Out of total 107 cases, 48 (44.85\%) were married. (Table 6). Out of 48 married females, prevalence of infertility was $66.66 \%$ with $58.33 \%$ cases of primary infertility while $8.33 \%$ cases of secondary infertility (Table 7). History of regular intake of junk foods was given by $57.94 \%$ cases. (Table 8 ) Sedentary lifestyle was observed in $49.53 \%$ cases. (Table 9))

\section{DISCUSSION}

Lifestyle changes including inclination of eating more junk food with high calories (57.94\%) has been found to be having more prevalence of PCOS as it is shown in the present study. Similar results were also shown by Elise Coker et al(13) These results suggest that women with PCOS have a poorer quality of life related to eating, and increased eating disorder pathology than other non-PCOS women. Present study suggests increase in incidence of adolescent PCOS (39.25\%) Franks S. has established the fact in his study(14) that adolescent PCOS is related with not only genetic factors but association of obesity and nutritional status also has great effect. The increasing incidence of childhood obesity has resulted in an alarming Increase not only in distressing symptoms but also impaired glucose tolerance and even diabetes among adolescent girls with PCOS Present study also shows the fact that adolescent girls have high prevalence $(44.93 \%)$ of PCOS. Johem et al(15) noted that Infertility was found by $72 \%$ of 309 women reporting PCOS and Infertility was 15 -fold higher in women reporting PCOS (Adjusted odds ratio 14.9, 95\% CI 10.9-20.3) Here in this study, incidence was found to be $66.66 \%$. J. Holte(16) found that when this constitution of PCOS is exposed to unlimited food supplies and modern sedentary lifestyle a full-blown PCOS with insulin resistance and infertility is triggered, presumably via several mechanisms, which follow a logical amplification system between two basic anabolic hormones, insulin and testosterone. Several studies have demonstrated that even a 5-10\% loss in bodyweight can restore menstrual cyclicity and ovulation.(17.18) In our present study, sedentary lifestyle in PCOS women was found to be $49.53 \%$ and incidence of obesity was found to be $45.79 \%$. It was found out that $57.94 \%$ PCOS women were eating outside junk food with high calories. The reported prevalence of obesity in women with PCOS has varied greatly depending on population and ethnicity, but it could be approximately 50\% (19-20). Recently, it was demonstrated that the prevalence of obesity among women with PCOS in the USA had increased from $51 \%$ in 1987 to $74 \%$ in 2002, paralleling the corresponding increase of obesity in the general population.(21) Exercise as the only intervention has also been demonstrated to improve fertility, insulin sensitivity and cardiopulmonary functional capacity in women with PCOS.(22) Glucose intolerance in normal-weight women with PCOS is uncommon, whereas approximately $40 \%$ of obese patients are affected. (23) Thus, obesity worsens all endocrine and metabolic features of PCOS. In fact, obesity as such, independent of PCOS, is associated with hyperandrogenism, insulin resistance, anovulation and reproductive impairments.(24)

\section{CONCLUSIONS}

Though PCOS is a heterogeneous endocrine disease having genetic factors, environmental and nutritional factors affect its incidence a lot. Eating high calorie food with sedentary lifestyle and obesity affect the incidence and severity of PCOS. We have found in the present study that incidence of anovulatory infertility is also high. Since PCOS is a lifestyle disease adversely affecting fertility and physical appearance of the person, it can be prevented by modification of lifestyle, enabling girls to live a healthy life. Diet with exercise resulting in weight loss is the most successful strategy to improve reproductive and metabolic parameters of PCOS. Encouragement of lifestyle changes with low calorie diet and active lifestyle helps to improve menstrual regularity and hence fertility in women suffering from PCOS. 


\section{REFERENCES}

[1] Umland EM, Weinstein LC, Buchanan EM. Menstruationrelated disorders. In: DiPiro JT, Talbert RL, Yee GC, et al. eds. Pharmacotherapy: a pathophysiologic approach. $8^{\text {th }}$ edn. New York: McGraw-Hill 2011: p. 1393.

[2] Azziz R, Woods KS, Reyna R, et al. The prevalence and features of the polycystic ovary syndrome in an unselected population. J Clin Endocrinol Metab 2004;89(6):2745-9.

[3] Sirmans SM, Pate KA. Epidemiology, diagnosis and management of polycystic ovary syndrome. Clin Epidemiol 2014;6:1-13.

[4] Amsterdam ESHRE/ASRM-sponsored 3rd PCOS Consensus Workshop Group. Consensus on women's health aspects of polycystic ovary syndrome (PCOS). Hum Reprod 2012;27(1):14-24.

[5] Azziz R, Sanchez LA, Knochenhauer ES, et al. Androgen excess in women: experience with over 1000 consecutive patients. J Clin Endocrinol Metab 2004;89(2):453-62.

[6] Diamanti-Kandarakis E, Kandarakis H, Legro RS. The role of genes and environment in the etiology of PCOS. Endocrine 2006;30(1):19-26.

[7] Abbott DH, Dumesic DA, Franks S. Developmental origin of polycystic ovary syndrome - a hypothesis. J Endocrinol 2002;174(1):1-5.

[8] Franks S, McCarthy MI, Hardy K. Development of polycystic ovary syndrome: involvement of genetic and environmental factors. Int J Androl 2006;29(1):278-85: discussion 286-90.

[9] Shannon M, Wang Y. Polycystic ovary syndrome: a common but often unrecognized condition. J Midwifery Women's Health 2012;57(3):221-30.

[10] Balen AH, Conway GS, Kaltsas G, et al. Polycystic ovary syndrome: the spectrum of the disorder in 1741 patients. Hum Reprod 1995;10(8):2107-11.

[11] Azziz R, Woods KS, Reyna R, et al. The prevalence and features of the polycystic ovary syndrome in an unselected population. J Clin Endocrinol Metab 2004;89(6):2745-9.

[12] Rotterdam ESHRE/ASRM-Sponsored PCOS Consensus Workshop Group. Revised 2003 consensus on diagnostic criteria and long-term health risks related to polycystic ovary syndrome. Fertil Steril 2004;81(1):19-25.
[13] Coker E, Lahoud R, Abraham S. Polycystic ovarian syndrome and eating disorder quality of life: a pilot study. JFIV Reprod Med Genet 2016;4:171. doi:10.4172/23754508.1000171

[14] Franks S. Polycystic ovary syndrome in adolescents. International Journal of Obesity 2008;32(7):1035-41.

[15] Joham AE, Teede HJ, Ranasinha S, et al. Prevalence of infertility and use of fertility treatment in women with polycystic ovary syndrome: data from a large communitybased cohort study. Journal of Women's Health 2015;24(4):299-307.

[16] Holte J. Disturbances in insulin secretion and sensitivity in women with the polycystic ovary syndrome. Baillieres Clin Endocrinol Metab 1996;10(2):221-47.

[17] Hoeger KM, Kochman L, Wixom N, et al. A randomized, 48week, placebo-controlled trial of intensive lifestyle modification and/or metformin therapy in overweight women with polycystic ovary syndrome: a pilot study. Fertil Steril 2004;82(2):421-9.

[18] Palomba S, Giallauria F, Falbo A, et al. Structured exercise training programme versus hypocaloric hyperproteic diet in obese polycystic ovary syndrome patients with anovulatory infertility: a 24 -week pilot study. Hum Reprod 2008;23(3):642-50.

[19] Balen AH, Conway GS, Kaltsas G, et al. Polycystic ovary syndrome: the spectrum of the disorder in 1741 patients. Hum Reprod 1995;10(8):2107-11.

[20] Escobar-Morreale HF, San Millan JL. Abdominal adiposity and the polycystic ovary syndrome. Trends Endocrinol Metab 2007;18(7):266-72.

[21] Yildiz BO, Knochenhauer ES, Azziz R. Impact of obesity on the risk for polycystic ovary syndrome. J Clin Endocrinol Metab 2008;93(1):162-8.

[22] Vigorito C, Giallauria F, Palomba S, et al. Beneficial effects of a three-month structured exercise training program on cardiopulmonary functional capacity in young women with polycystic ovary syndrome. J Clin Endocrinol Metab 2007;92(4):1379-84.

[23] Dunaif A. Insulin resistance and the polycystic ovary syndrome: mechanism and implications for pathogenesis. Endocr Rev 1997;18(6):774-800.

[24] Pausquali R, Pelusi C, Genghini S, et al. Obesity and reproductive disorders in women. Hum Reprod Update 2003;9(4):359-72. 